\title{
IMAGING PROFILE OF CHILDREN BIRTH TO 12 YEARS PRESENTING WITH FIRST URINARY TRACT INFECTION (UTI) AT A TERTIARY CARE HOSPITAL
}

\author{
Yengkhom Rameshwor Singh ${ }^{1}$, Okram Pusparani Devi², Tonjam Hemchand Singh ${ }^{3}$ \\ ${ }^{1}$ Assistant Professor, Department of Paediatrics, JNIMS, Imphal. \\ ${ }^{2}$ Assistant Professor, Department of Radiodiagnosis, JNIMS, Imphal. \\ ${ }^{3}$ Assistant Professor, Department of Psychiatry, JNIMS, Imphal.
}

\begin{abstract}
Imaging of the urinary tract is recommended for all children with UTI. The aim of these investigations is to identify patients at risk of renal damage, mainly those below 5years of age, with vesicoureteric reflux (VUR) or urinary tract obstruction. This study was designed and conducted in the department of Pediatrics and department of Radiodiagnosis, BVDU Medical college hospital, Pune during the period from July 2009 to August 2011 to do imaging studies as per protocol of investigations suggested by the Indian Pediatric Nephrology Group of children from birth to 12 years of age presenting with their first culture positive UTI who attended our tertiary care centre. Abnormal USG was found in $40.3 \%$ cases and helped to identify hydroureteronephrosis (HUN) and calculi. Micturating cystourethrography (MCU) examination was abnormal in $31.1 \%$ cases. Of which, $22.2 \%$ patients had VUR suggesting that VUR is common in culture positive UTI, thus stressing the need of MCU in patients of culture positive UTI. DMSA scintigraphy (DMSA) showed scar in 56\% of total cases examined indicating need for doing DMSA whenever indicated and for prognostication. One single imaging modality is not sufficient to evaluate children with UTI.
\end{abstract}

KEYWORDS: UTI, USG, MCU, DMSA, VUR, Hydroureteronephrosis.

HOW TO CITE THIS ARTICLE: Yengkhom Rameshwor Singh, Okram Pusparani Devi, Tonjam Hemchand Singh. "Imaging Profile of Children Birth to 12 Years Presenting with First Urinary Tract Infection (UTI) at a Tertiary Care Hospital". Journal of Evolution of Medical and Dental Sciences 2015; Vol. 4, Issue 90, November 09; Page: 15582-15588, DOI: 10.14260/jemds/2015/2235.

INDRODUCTION: Urinary tract infection (UTI) is a common infection in infants and children. Rapid evaluation and treatment of UTI is important to prevent renal parenchymal damage (Renal scarring) that can cause hypertension, toxaemia of pregnancy, chronic renal failure and end-stagerenal disease later. Risk factors for renal scarring include: young age especially children less than one year old, delay in initiating antibacterial treatment, recurrent UTI, and presence of moderate to severe VUR.(1,2)

Imaging of the urinary tract is recommended for all children with UTI. The aim of these investigations is to identify patients at risk of renal damage, mainly those below 5years of age, with VUR or urinary tract obstruction. The following is the protocol of investigations suggested by the Indian Pediatric Nephrology Group in the consensus statement on management of urinary tract infection. ${ }^{(2)}$

$20 \%$ of children with urinary tract infections have an underlying structural abnormality of the urinary tract, three-fourth of which are picked up on ultrasound. In addition, a micturating cystourethrography (MCU) is also indicated in all boys below 2 years with UTI, since one-third of anomalies will be missed if only ultrasound is done. $(3,4,5)$ In one study VUR was identified in 106 of 171 kidney units when MCU was done following the first UTI.(6)

DMSA renal scan is the best mode for evaluation of renal parenchymal involvement. During the acute infection it can detect focal pyelonephritis and later show renal scars.

Financial or Other, Competing Interest: None.

Submission 19-10-2015, Peer Review 20-10-2015,

Acceptance 28-10-2015, Published 09-11-2015.

Corresponding Author:

Yengkhom Rameshwor Singh,

Thoubal Haokha, Maning Leikai, P. O,

Thoubal-795138, Manipur.

E-mail:drrameshwor@gmail.com

DOI:10.14260/jemds/2015/2235.
DMSA scan should be done as a follow up investigation as a scan during acute infection does not predict development of permanent scars. ${ }^{(7,8)}$

The present study was designed to do imaging studies of children from birth to 12 years of age presenting with their first UTI in our tertiary care centre.

MATERIAL AND METHODS: This observational study was conducted in the department of Pediatrics and department of Radiodiagnosis, BVDU Medical college hospital, Pune during the period from July 2009 to August 2011. After obtaining informed consent 52 patients from birth to 12 years of age with urine culture positive first urinary tract infection was enrolled. Inclusion criteria: Children birth-12 years of age with positive urine culture.

Exclusion Criteria: Children with recurrent UTI. Detailed clinical history taking, general and systemic examinations were done. Investigations that include hemoglobin, TLC, DLC, blood urea and serum creatinine, urinalysis, urine culture and sensitivity tests were done for all patients. Imaging of urinary tract that include renal USG, micturating cystourethrography (MCU), 99mTc-dimercaptosuccinic acid scintigraphy (DMSA) and in some cases Ethylene dicysteine renal scan (EC renal scan), 99mTc-diethylenetriaminepentaacetic acid scan (DTPA scan) and Intravenous pyelography (IVP) were done whenever relevant as per protocol recommended by Indian Paediatric Nephrology Group..

RESULT: Fifty two (52) children with first UTI formed the study material and were evaluated. Of this 52 children, 31 were males and 21 were females with male to female ratio of 1.47:1. Imaging done as per protocol and results are shown in Figure 1. USG was done in all patients in this study group (Fig. 1). $31(59.6 \%)$ patients had normal USG findings. Remaining $21(40.4 \%)$ patients had abnormal USG as shown in Table 2. 
As expected, some of the patients had more than one abnormality on USG. Of 52 patients, MCU was done in 44(84.6\%) patients (Fig. 1). Of which, 29(65.9\%) were normal, remaining 15(34.1\%) patient had abnormal findings on MCU as shown in Table 3. As per protocol, for children greater than 5 years of age with normal USG no further investigation was done. MCU was not done in 7 patients, of which MCU was not indicated in 4 cases $(>5$ years and normal USG), 1 patient parents were not willing and 2 other patients were considered immunosuppressed and hence predisposed to infection and did not warrant further investigation. Some patients had more than 1 abnormality on MCU.

VUR was detected in $10(22.2 \%)$ cases. $6(60 \%)$ patients had primary VUR and $4(40 \%)$ had secondary VUR secondary to posterior urethral valves (PUVs). Of 52 patients, DMSA was done after 3 months in $25(48 \%)$ cases. It was not indicated as per protocol in 9 cases and either not done due to financial constraints or patients did not follow up for DMSA in 18 cases (Fig. 1). Of 25 patients who underwent DMSA, 11(44\%) had a normal scan and 14(56\%) had abnormal findings in the form of poor/irregular tracer uptake with cortical cold areas suggestive of renal scars.

Ethylene Dicysteine (Ec) Renal Scan: EC renal scan was done in 2 infants, 1 was a 2 month old infant with USG showing right HUN, normal MCU and a scarred right kidney on DMSA. EC scan showed enlarged, poorly functioning, hydronephrotic obstructed right kidney (PUJ obstruction). The other one was a 3 months old child, a case of bilateral ectopic ureters, USG showed bilateral HUN, MCU showed grade V right VUR, DMSA showed no scar. EC scan showed hydronephrotic obstructed left kidney with preserved function and sub optimally functioning non-obstructed right kidney.

99m Tc-Diethylenetriamine Pentacetic Acid (Dtpa) Scan: DTPA scan was done in 2 cases; 1 was a case of neurogenic bladder. USG showed bilateral HUN, MCU was suggestive of neurogenic bladder, DMSA showed a scar on left kidney. DTPA scan showed normally functioning mildly hydroureteronephrotic, non-obstructed left kidney. Another was a case of left HUN on USG, VUR on MCU with scar on DMSA. DTPA showed small satisfactorily functioning hydronephrotic non-obstructed left kidney with evidence of scar.

Intravenous Pyelography (IVP): IVP was done in 3 cases. 1 was a case of left PUJ obstruction. USG showed left HUN, DMSA showed scar and MCU was normal. IVP showed bilaterally normally functioning kidneys, fullness of left pelvicalyceal system with probable vascular impression at PUJ. Another was a case of congenital megaureter, USG showed left HUN with dilated ureter, MCU and DMSA were normal. IVP showed left peivicalyceal fullness with tortuous and grossly dilated left ureter-congenital megaureter. The third was a case of duplex moiety. USG showed duplex moiety on left side and absent right kidney, MCU showed VUR grade IV on left side, DMSA showed no scar but smaller right moiety compared to left. DTPA confirmed double moiety on left side with hydroureteronephrosis (HUN) of lower moiety.
DISCUSSION: USG has almost completely replaced IVP for assessing the gross anatomy of the urinary tract, and it is routinely performed after the diagnosis of a first UTI. It is a noninvasive test that can demonstrate the size, shape, number, location of the kidneys, the presence of duplication and dilatation of the ureters, the presence of ureteroceles, bladder wall thickness, and the existence of gross anatomical abnormalities, such as horseshoe kidney. However, USG is not sensitive enough to detect acute pyelonephritis, VUR and renal scarring. MCU is very sensitive and specific in detecting VUR and DMSA for acute pyelonephritis and renal scar.

USG and MCU in Diagnosis of VUR: In a comparative study by Tan Chee et al, 55 children with culture positive UTI were studied by both USG and MCU, 17 patients with VUR on MCU, only 3 were reported to have abnormal USG, and supported the impression that USG is deficient in accurately excluding VUR.(9)

Our study also had similar findings, in 10 cases of VUR on MCU, 3 had normal USG findings.In a study of Shrestha et al, 145 MCUs were done in children with UTI, of which $24 \%$ were positive for VUR and the most common age group was between 2 to 12 months and the male to female ratio was $1: 2: 1$. More than $60 \%$ had bilateral VUR.(10) In our study $22.2 \%$ had VUR detected by MCU, bilateral in $50 \%$ cases with male to female ratio of 9:1 and $50 \%$ cases in age group less than 2 years. This finding is similar to findings by Shrestha et al. In the study by Theodoros A et al also found VUR in $20 \%$ cases of culture positive UTI, $50 \%$ unilateral and $50 \%$ bilateral, similar to our findings.(11)

MCU and Structural Anomalies of the Urinary Tract: In a study by Jothilakshmi et al about the association of structural abnormalities of the urinary tract in children with UTI using USG, 262 children with culture proven UTI were studied, 54 patients had an underlying urinary tract anomaly; 42 were picked up by ultrasound and 12 by MCU. Children less than 2 years had the highest incidence of anomalies. One-third of anomalies would have been missed if only ultrasound was done.(12) In our study, of 52 patients with culture positive UTI, congenital anomalies of urinary tract was found in $23 \%$ of cases.

Technetium-99m-Labeled Dimercaptosuccineic Acid Scan (Dmsa Scan): In our study, of 25 patients who underwent DMSA, $44 \%$ had a normal scan and $56 \%$ had abnormal findings suggestive of renal scars. In study by Nammalwar et al, 68 children with UTI, 92.9\% had features of acute pyelonephritis in the DMSA done during acute episode of infection, of these $82.1 \%$ had VUR. In $33.3 \%$ only there was persistence of scar after 6 months on repeat DMSA. DMSA is a useful investigation for the diagnosis of acute pyelonephritis in febrile UTI. An abnormal DMSA is a strong indication for work up for VUR.(13)

Comparison of USG, MCU and DMSA in children with UTI: In a hospital based study by Smellie JM et al, comparing 4 methods of investigation (USG, MCU, DMSA and IVU) in 58 children with UTI, all 4 investigations were normal in 12 children. In 36 with VUR on MCU, dilatation was reported on USG in 8 children. On DMSA renal scarring was seen in 20 children; it was suspected on USG in nine, with dilatation alone in four, and a normal report in seven. Duplex kidneys identified on IVU were unrecognized on USG or DMSA studies. 
This study suggests that USG is unreliable in detecting VUR, renal scarring, or inflammatory change and alone, is inadequate for investigating UTI in children.(14) In our study, in all those patients who had undergone DMSA, findings were compared with the findings of USG. Of the 25 patients, $16(64 \%)$ patients had abnormal USG findings, while 14(56\%) patients had abnormal DMSA findings.

In our study, in all those patients who had undergone DMSA scanning, their MCU findings were analyzed and compared with the findings of DMSA. Of 25 patients, 13(52\%) patients had abnormal MCU findings, while $14(56 \%)$ patients had abnormal DMSA findings. In the study by Hye-young Lee, Byung Hyun Soh et al, 32.7\% showed positive results on DMSA, of which VUR was present on MCU in $56.6 \%$ cases and in the remaining $29.8 \%$ DMSA was normal. USG was also normal in $29.8 \%$ of cases with VUR in MCU.(15)

Thus, similar to other hospital based studies, our study also shows that one single imaging modality is not sufficient to evaluate children with UTI. Though renal USG is the first imaging modality considered after an UTI, it cannot pick up all VUR and is very insensitive to identify renal scarring. Also, not all patients with abnormal renal USG or abnormal MCU have scar on DMSA. Conversely, all patients with scar on DMSA may not have abnormal USG or MCU.

Ethylene Dicysteine (EC) Renal Scan: EC renal scan which was done in 2 small infants with suspected obstruction and poor renal function as suggested by abnormal USGs, 1 normal and 1 abnormal MCU, 1 normal and 1 abnormal DMSA showed hydronephrotic obstructed kidneys with sub optimally functioning kidneys. Therefore, EC scan is useful in young infants for diagnosing obstructive lesions and renal function.

99m Tc-Diethylenetriaminepentacetic Acid (Dtpa) Scan: DTPA scan was done to estimate renal function (GFR) and to look for obstruction in 2 cases which was found helpful in estimating GFR and in diagnosing obstruction in urinary tract more specifically.

Intravenous Pyelography (IVP): Intravenous Pyelography (IVP) is useful in confirming duplication systems, function of kidneys and other anatomic abnormalities. In our study the procedure was performed in 3 cases and was found useful in diagnosing 1 case of PUJ obstruction, 1 congenital megaureter and 1 duplex moiety.

CONCLUSION: Abnormal USG was found in $40.3 \%$ cases and helped to identify hydroureteronephrosis and calculi. MCU examination was abnormal in $31.1 \%$ cases. Of which, $22.2 \%$ patients had VUR. This suggests that VUR is common in culture positive UTI, thus stressing the need of MCU in patients of culture positive UTI. DMSA showed scar in 56\% of total cases examined indicating need for doing DMSA whenever indicated and for prognostication. One single imaging modality is not sufficient to evaluate children with UTI.

\section{REFERENCES:}

1. Benador D., N. Benador, D. Slosman, B. Mermillod, and E. Girardin. Are young children at highest risk of renal sequelae after pyelonephritis? Lancet 1997; 349:17-19.

2. Bagga A, Babu K, Kanitakar M, Srivastava RN. Consensus statement on management of urinary tract infections. Indian Pediatric Nephrology Group. Indian Pediatrics 2001; 38:1106 - 1115.

3. American Academy of Pediatrics, Committee on Quality Improvement, Subcommittee on Urinary Tract Infections. Practice parameters: The diagnosis, treatment and evaluation of the initial urinary tract infections in febrile infants and young children. Pediatrics 1999; 103: 843 - 852.

4. Hoberman A, et a. Imaging Studies after a first Febrile Urinary Tract Infection in Young Children. N Engl J Med Jan 16 2003; vol. 348, No. 3:195 - 202.

5. Sik-Nin Wong, Niko Kei-Chiu Tse, Kwok-Piu Lee, et al. Evaluating different imaging strategies in children after first febrile urinary tract infection. Pediatr Nephrol, 2010; 25:2083-2091.

6. V. Bhatnagar, DK Mitra, S Agarwal, R Kumar, C Patel, AK Malhotra, AK Gupta. The role of DMSA scans in evaluation of the correlation between urinary tract infection, Vesicoureteric reflux and renal scarring. Pediatr Surg Int; 2002 Mar; 18(2-3): 128-134.

7. Beggi A, Dardanelli L, Pomero G, et al. Acute renal cortical scintigraphy in children with a first urinary tract infection. Pediatr Nephrol 2001; 16: 733-8.

8. Mukta M. Role of DMSA in Pediatric UTI. Indian Pediatrics March 17, 2006; 45: 270 -271.

9. Tan SM, Chee T, et al. Role of Renal Ultrasonography and micturating cystourethrogram in the assessment of VUR in Children and infants with UTI. SING MED J. 1988; 29: 150 152.

10. Shrestha S, Basukala S, et al. Primary vesicoureteric reflux. Nepalese children Kathmandu University Medical Journal 2008; Vol. 6, No. 1 Issue 21, 75 - 78.

11. Theodoros A, Kanellopoulos, Christos Salakos, et al. First urinary tract infection in neonates, infants, young children. Pediatr Nephrol 2006; 21: 1131-1137.

12. Jothilakshmi K, Bhoopathy V. Radiological Evaluation of the Urinary Tract in Children with Urinary Infection. Indian J Pediatr 2001; 68(12): 1131 - 1133.

13. Nammalwar BR. Vijaykumar M, Sankar J, Ramnath B, Prahlad N. Evaluation of the use of DMSA in culture positive UTI and culture negative acute pyelonephritis. Indian Pediatrics 2005; 42: 691 - 696.

14. Smellie JM, Rigden SP, et al. Urinary tract infection: a comparison of four methods of investigation. Archives of Disease in Childhood 1995; 72: 247 - 250.

15. Hye-young lee, Byung Hyun Soh, Chang Hee Hong, et al. The efficacy of ultrasound and dimercaptosuccinic acid scan in predicting vesicourethral reflux in children below the age of 2 years with their first febrile UTI. Pediatr Nephrol 2009, 24:2009-2013. 


\begin{tabular}{|c|c|c|c|c|}
\hline Age(years) & Male & Female & Total & Percentage (\%) \\
\hline$\leq 2$ & 15 & 12 & 27 & 51.9 \\
\hline$>2-5$ & 7 & 5 & 12 & 23.0 \\
\hline$>5$ & 9 & 4 & 13 & 25.0 \\
\hline \multicolumn{6}{|c|}{ Table 1: Age and Sex distribution (n=52) } \\
\hline
\end{tabular}

\begin{tabular}{|c|c|c|}
\hline USG Findings & $\begin{array}{c}\text { Number of } \\
\text { Patients }\end{array}$ & $\begin{array}{c}\text { Percentage } \\
(\%)\end{array}$ \\
\hline Normal & 31 & 59.6 \\
\hline HN with HU & 14 & 26.9 \\
\hline $\begin{array}{l}\text { Bladder wall thickening } \\
\text { with changes of cystitis }\end{array}$ & 9 & 17.3 \\
\hline HN (no hydroureter) & 3 & 5.7 \\
\hline $\begin{array}{c}\text { Chronic renal parenchymal } \\
\text { disease }\end{array}$ & 2 & 3.8 \\
\hline Ureteric calculus & 2 & 3.8 \\
\hline Single kidney & 1 & 1.9 \\
\hline Vesical calculus & 1 & 1.9 \\
\hline Cystic kidney & 1 & 1.9 \\
\hline Double moiety (left) & 1 & 1.9 \\
\hline Wilm's tumor & 1 & 1.9 \\
\hline
\end{tabular}

\begin{tabular}{|c|c|c|}
\hline MCU Findings & $\begin{array}{c}\text { Number of } \\
\text { Patients }\end{array}$ & $\begin{array}{c}\text { Percentage } \\
\text { (\%) }\end{array}$ \\
\hline Normal & 29 & 65.9 \\
\hline Bilateral VUR & 5 & 11.1 \\
\hline Unilateral VUR & 5 & 11.1 \\
\hline Trabeculated bladder & 2 & 4.4 \\
\hline Urethral stricture & 1 & 2.2 \\
\hline Dilated posterior urethra & 6 & 13.3 \\
\hline Bilateral ectopic ureters & 1 & 2.2 \\
\hline \multicolumn{2}{|c|}{ Table 3: Distribution of cases according to } \\
micturating cystourethrogram (MCU) findings (n=44) \\
\hline
\end{tabular}

\begin{tabular}{|c|c|c|}
\hline MCU Findings & $\begin{array}{c}\text { Number of } \\
\text { Patients }\end{array}$ & $\begin{array}{c}\text { Percentage } \\
\text { (\%) }\end{array}$ \\
\hline Primary VUR & 6 & 60 \\
\hline Secondary VUR & 4 & 40 \\
\hline Total & $\mathbf{1 0}$ & $\mathbf{1 0 0}$ \\
\hline \multicolumn{2}{|c|}{ Table 4: Distribution of cases } \\
according to type of VUR (n=10)
\end{tabular}

\begin{tabular}{|c|c|c|}
\hline DMSA Findings & $\begin{array}{c}\text { Number of } \\
\text { Patients }\end{array}$ & $\begin{array}{c}\text { Percentage } \\
\text { (\%) }\end{array}$ \\
\hline Normal & 11 & 44 \\
\hline $\begin{array}{c}\text { Abnormal } \\
\text { (Cortical cold areas/Scars) }\end{array}$ & 14 & 56 \\
\hline $\begin{array}{c}\text { Table 5: Distribution of patients according to findings } \\
\text { of DMSA scintigraphy (99mTc-dimercaptosuccinic acid) }(\mathbf{n}=\mathbf{2 5})\end{array}$ \\
\hline
\end{tabular}



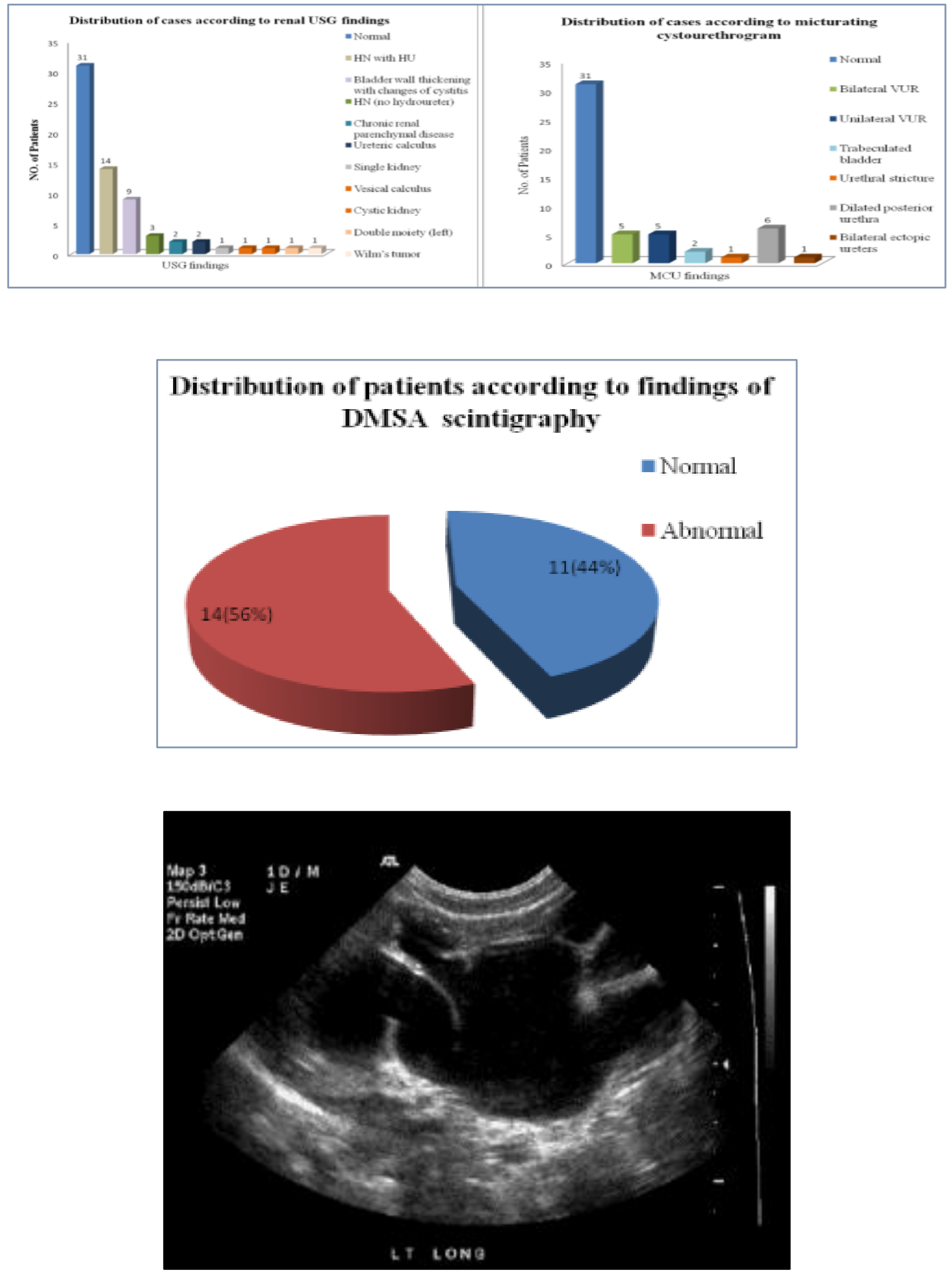

Image 1: USG image of hydroureteronephrosis of a child in this study cohort 


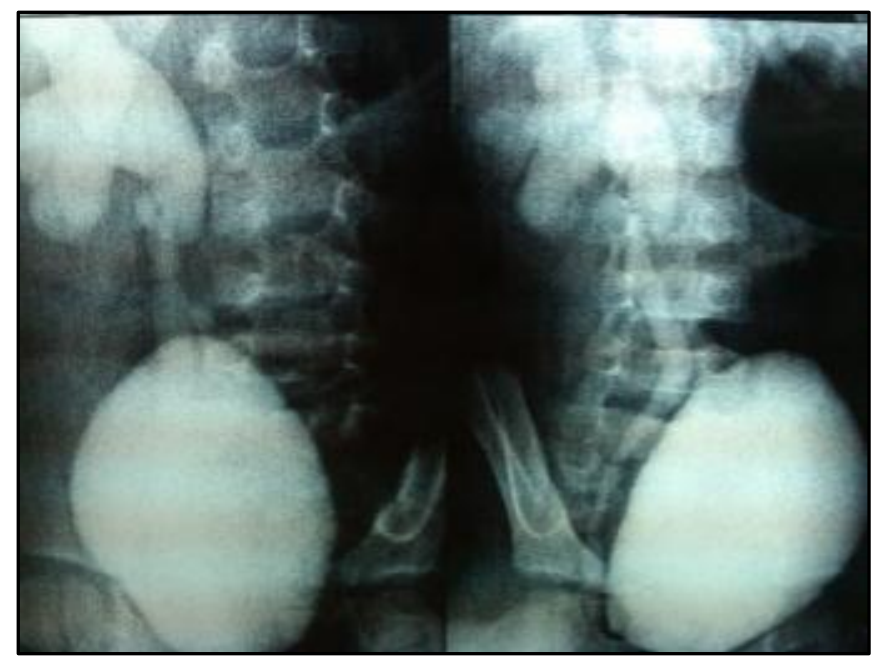

Image 2: MCU image of a case of VUR grade $V$ on right side in this study cohort

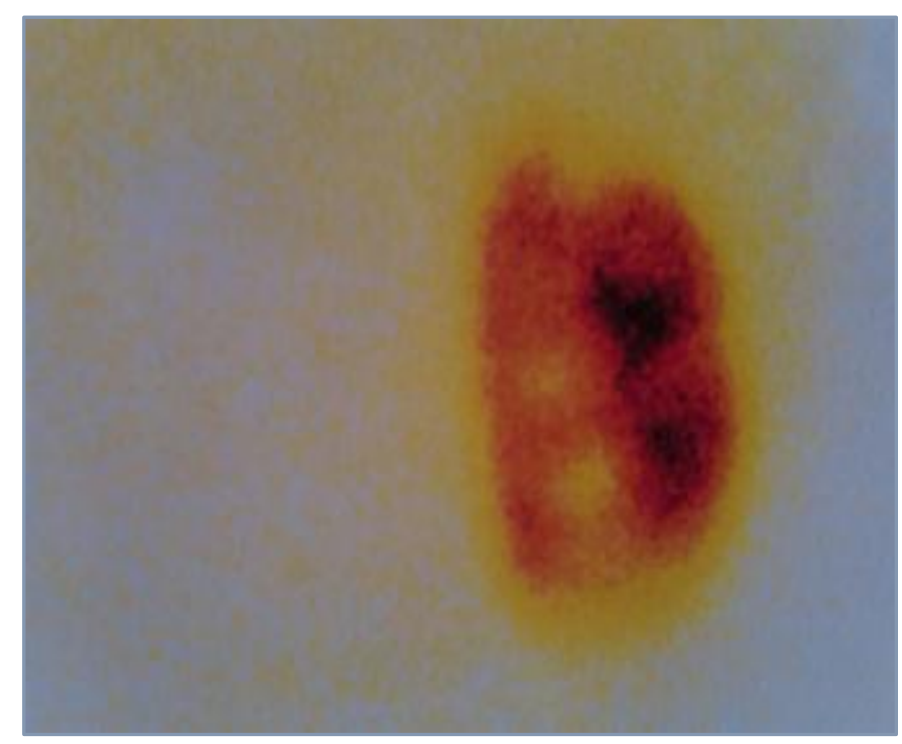

Image 3: DMSA Scan Image showing poor tracer uptake with cortical cold areas suggestive of scars in this study cohort

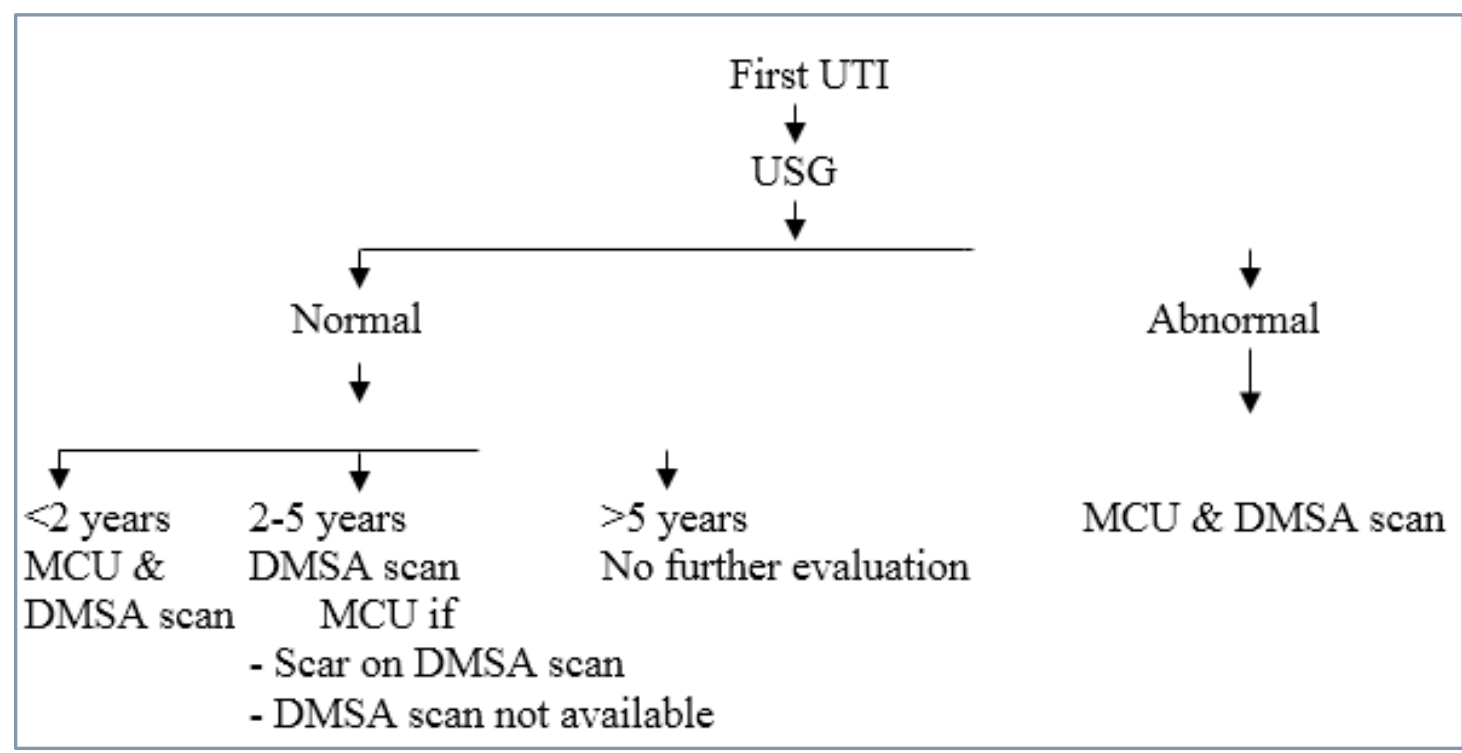




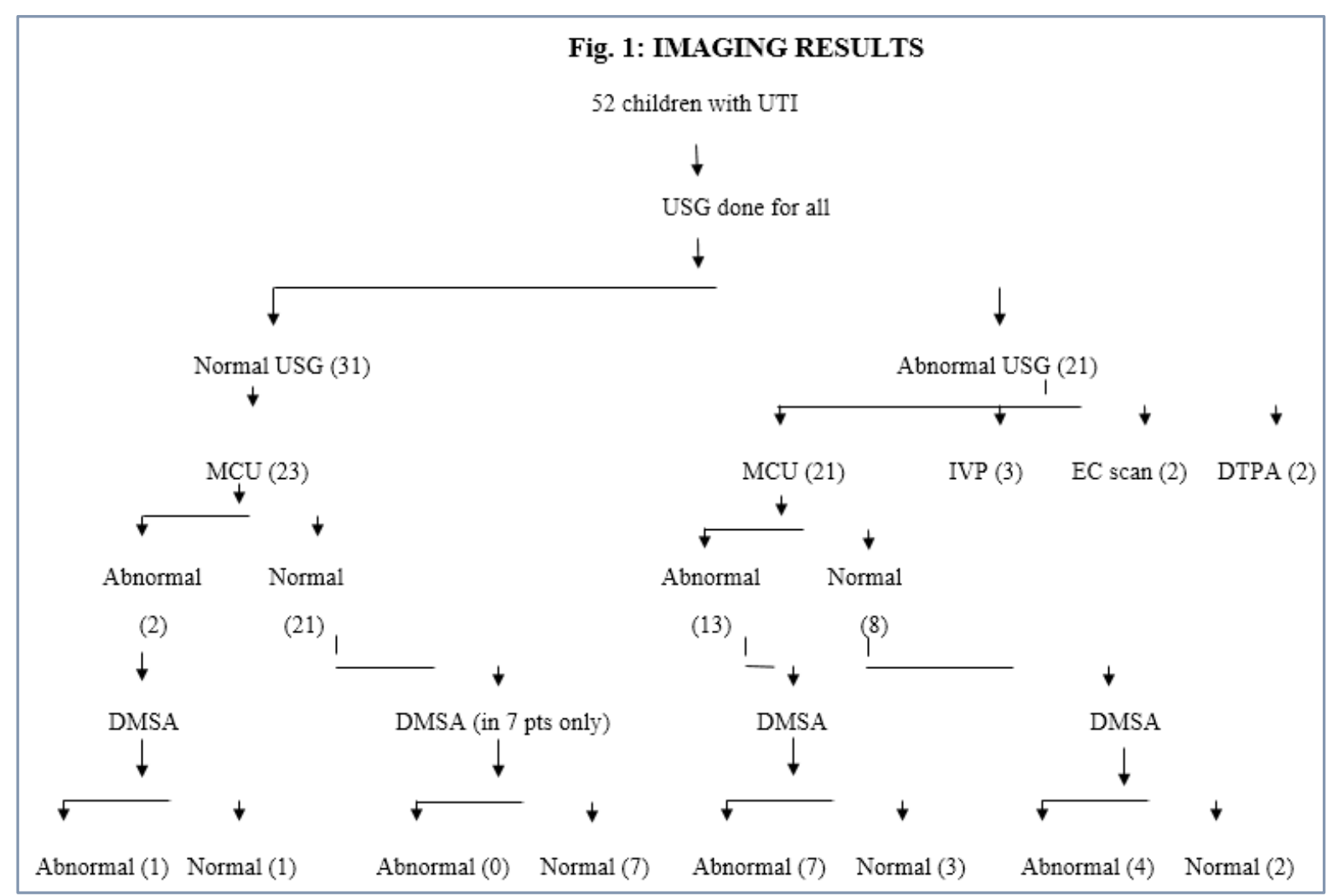

